\title{
People Living With Epilepsy Exploring socio cultural determinants affecting their life
}

\author{
Ajita Rani ${ }^{1}$, Upmesh K.Talwar ${ }^{2}$, Ravinder Singh ${ }^{3 *}$, V K S Gautam ${ }^{4}$ \\ ${ }^{1}$ Assistant Professor, Department of Psychology, Government Raza P.G. College, Rampur, UP India \\ ${ }^{2}$ Assistant Professor \& Head, Department of Social Work, Model Public Education College, M.J.P. University, Barielly, UP, India \\ ${ }^{3}$ Associate Professor \& Head, Department of Medical Anthropology IHBAS Hospital, Dilshad Garden, Delhi-110095, India \\ ${ }^{4}$ Assistant Professor, Department of Neurosurgery, IHBAS Hospital, Dilshad Garden, Delhi-110095, India \\ *Corresponding author E-mail: medicalanthropology.ihbas@gmail.com
}

\begin{abstract}
Socio-cultural determinants affecting People Living with Epilepsy (PLWE) were explored between August 2010 and November, 2011 in Bareilly district of North India. Results reveal various aspects of their life: onset of first seizure, duration of suffering, their perception about daily life, marriage, family burden, etc. Further, it explored their activities during before and after treatment? PLWE face Stigma in the family as well as in their community. The capacity to do work and earn and expenditure incurred on hospital visits were major determinants affecting their life. Relationship of PLWE with other people and involvement in Community are other crucial socio-cultural determinants affecting their life.
\end{abstract}

Keywords: Epilepsy, PLWE, Seizure, Stigma.

\section{Introduction}

Epilepsy is a common neurological disorder of brain function. It is a syndrome of different symptoms involving episodic abnormal electrical activity in the brain (Rani, 2012). It may develop after a particular identifiable event (e.g. asphyxia, head injury, meningitis etc.) such epilepsy known as symptomatic epilepsy or it may develop without any identifiable cause then it is called idiopathic epilepsy. It is estimated that about 10 million people may be suffering from epilepsy in India (Degen, Degen and Roth, 1990).

A review of epidemiology of epilepsy from urban population and rural areas have rate of 5.38 per 1000 (Sridharan, 2003). Similar prevalence has been observed in some community based studies in Banglore, Kerala and in rural North West India (Pal, Das and Sengupta, 1998; Pal, Nandy and Sander, 1999; Gourie-Devi, Gururaj and Satishchandra, 2004; Gourie Devi et al, 2004).

Paper explores the socio-cultural determinants which include cultural beliefs associated with epilepsy in Bareilly, a district of North-West of Uttar Pradesh, India. There is one district Mental Hospital and are other private neuro-clinics where epilepy patients visit. It aims to investigate behavior, social burden of care in family, economic decision making, education and influences of peer groups and problems in employment, if any. Moreover, it also assesses awareness about epilepsy, local healing practices and associated faith-spirit possession relating to epilepsy and stigma, if any.

\section{Material and research methods}

Patients were selected through purposive sampling from the district mental hospital and other private neuro-clinics in Bareilly district of North-West of Uttar Pradesh, India. Their care provider or accompanied persons were also included as the informant. A semi structured bilingual (Hindi and English) schedule was used for detail. An informed consent was also obtained either from patient or from their care giver.

\section{Results}

There were limitations and constraints while conducting this study. In hospital situations most patients were not interested to be interviewed and wanted to go back home early. In field based situations, the long travelling distance was a major constraint. Care givers of some female patients did not allow us to interview them. So their number is relatively less. Another constraint of recruiting patients was the social stigma associated with this disease. Therefore, we could only gather the detail information from 58 patients, less than the initial target of 100 cases of epilepsy. Therefore we could only gather the information from 58 patients and the analysis as follows.

1) The average age of 58 patients ranges from 19 to 28 years (Table-1)Demographic information about sex, residence, marriage, religion, and education of patients and parents, type of family, professions and members in the family have been summarized(Table-2).

Table 1: Age of the Epilepsy Patients $(\mathrm{N}=58)$ :

\begin{tabular}{lll}
\hline Age Range(ys) & No(58) & \%age \\
\hline$<20$ & 28 & 48.0 \\
$21-25$ & 27 & 46.6 \\
$26-30$ & 03 & 5.2 \\
\hline
\end{tabular}

There were 70.7 percent male and 29.3 percent female patients in our sample. About 60 percent patients were from the rural area as compared to 39 percent patients from the urban area. More than ninety percent (54) patients with epilepsy are unmarried as com- 
pared to six percent (4) as married. 63 percent PLWE were Hindus, 32 percent Muslims and 3.4 percent were Christians. The review of educational status of the patients revealed that most of the patients were well educated-43.1 percent patient were educated up to 10th class followed by 36.2 percent above 10th class. Parents of the patients were well educated, particularly father, 56.9 percent were educated above 10th class followed by 32 percent as illiterate. Similarly more than 50 percent mothers were educated up to 10th class followed by 27.6 percent mothers as illiterate. 62 percent of the patients were living in the nuclear family as compared to 37.9 percent patients stay in the joint family. Most of the patients were agriculturist 41 percent, 56.9 percent in service and 1.7 percent patients were the students (Table-2).

Table 2: Demographic profile of People with Epilepsy $(\mathrm{N}=58)$ :

\begin{tabular}{llll}
\hline Variable & & No. & $\%$ \\
\hline Sex & Male & 41 & 70.7 \\
Residence & Female & 17 & 29.3 \\
\multirow{3}{*}{ Marriage } & Rural & 35 & 60.3 \\
& Urban & 23 & 39.7 \\
Religion & Married & 04 & 06.9 \\
& Unmarried & 54 & 93.1 \\
\multirow{3}{*}{ Education Patient } & Muslim & 19 & 32.8 \\
& Hindu & 37 & 63.8 \\
Father of Patient & Christian & 02 & 03.4 \\
& Illiterate & 12 & 24.7 \\
& $<10^{\text {th }}$ class & 25 & 43.1 \\
Mother of Patient & $>10^{\text {th }}$ class & 21 & 36.2 \\
& Illiterate & 14 & 32.8 \\
& $<10^{\text {th }}$ class & 11 & 18.9 \\
Family & $>10^{\text {th }}$ class & 33 & 56.9 \\
Patient Profession & Illiterate & 16 & 27.6 \\
& $<10^{\text {th }}$ class & 30 & 51.7 \\
& $>10^{\text {th }}$ class & 12 & 20.7 \\
& Nuclear & 36 & 62.1 \\
& Joint & 22 & 37.9 \\
& Agriculture & 24 & 41.4 \\
& Service & 33 & 56.9 \\
& Student & 01 & 1.7
\end{tabular}

Age at the first seizure: 34.5 percent patients expressed the first episode of seizure between 16 to 20 years followed by 29.3 percent when they were between 11 and 15 years of the age, 20.7 percent experienced first seizure when they were below 5 years and 15.5 percent patients have mentioned about first seizure when they were between 6 and 10 years of age.

Duration of Seizure: The duration of epilepsy suffering among the people with epilepsy show about 39.7 percent patients were suffering for five years, followed by 29.3 percent for the six to ten years. The patients suffering for 11 to 15 years are 18.7 percent and 12.1 percent patients suffer about 20 years with epilepsy.

Treatment and Knowledge about the Epilepsy: None of the patients in this stdy took community treatment. 44.8 percent people took the allopathic or homeopathic treatment where as 38 percent patients took the allopathic treatment.

More than 86 percent had heard about epilepsy in contrast to 13.8 percent patients never heard about epilepsy as disease. About 62 percent patients think epilepsy is mental or physical disease. Whereas 37.9 percent patients still believe it as supernatural disease. 79.3 percent patients expressed that it can be treated like other diseases as compared to 20.7 percent patients have believe it cannot be treated. Epilepsy had disturbed the daily routine among the 46.7 percent patients whereas about 53 percent do not have disturbance in day to day activities. 51.7 patients did not want to marry because of the epilepsy whereas 44.8 percent patients thought that they can marry despite of disease. 3.5 percent patients were indecisive about their marriage plan. About the 31 percent of PLWE sought cure form the masjid, peer, tabeej, scared thread etc. for Epilepsy. Whereas 69 percent patients neither visited such healers nor sought treatment. Besides, there were other diseases like anemia for which they also visit such religious sites-masjid, mazar etc.

Family Burden: Family burden was assessed through a qualitative scale to map the degree of economic stress on the family. It was noticed 65.5 percent patients and their family economically felt as capable to some extent and 6.9 percent much more capable to meet expenses of their epilepsy patients.

However, 27.6 percent families of patients were not economically capable to meet expenses of their patients. 60.3 percent patients mentioned that their family was responsible to some extent for economic needs, whereas 29.3 percent patients were much more responsible to the family economics need and only 10.3 percent patients were not at all responsible for the family economic needs. Family members were worried about economic responsibilities of the patients in future. 58.6 percent patient's family is worried for future to some extend whereas 31.1 percent patient's family worried much more and 10.3 percent patient's family do not worry at all. 48.3 percent Families were economically disturbed to some extent, 15.5 percent families were much more disturbed economically 36.2 percent are not at all disturbed economically. 51.7 percent patients were not disturbed for the jobs, 27.6 were disturbed to some extend followed by 20.7 percent patients who were much more disturbed for the job.

Another issue was how do Patients reach to the hospital? Patients visit city hospital form different neighboring districts to Barilly, 44.8 percent ; Barabanki, 24.1 percent; Shahjanpur,15.5 percent; Badaun, 5.2 percent; followed by Unnav, Pilibhit, Sitapur, 3.4 percent each. 32.4 percent patients reach within one hour of their journey whereas 22.4 percent patients take at least 2 hours to reach the hospital; 17.2 percent patients take between 2 and 3 hours to reach the hospital and 27.6 percent patients take more than three hours to come to the hospital.

More than 51 percent patients spend more than 150 rupees to visit the hospital; 20.3 percent patients spend between 100 and 150 rupees followed by 17.2 percent patients spend between 50 and 100 rupees.

Patients are accompanied by the core family members. 51.7 patients are accompanied by father followed by 24.1 percent patients with the mother, 17.2 by brother but none is accompanied by sister of the patients. Only 6.9 percents of the associated with the relative for the hospital visit. 41.4 percent of the patients are referred by the Doctor followed by 29.3 percent referred by relatives and 24.1 percent referred by neighbors. More than 65 percent patients visited the hospital for the first time for the consultation.

About 65.8 percent patients have been visiting for the five months followed by the 13.8 percent patients are visiting the hospital for the between 5 and 10 months and 20.7 percent patients have been visiting the hospital for more than 10 months. Nearly 57 percent patients have been benefitted from the treatment as compared to 43.1 percent reveal who said that there was no benefit from the treatment. Further 48.3 percent patients felt treatment benefit was much more whereas 37.9 percent patients felt benefit was less. The frequency of the hospital visit of the 51.7 percent patients is once in a month, 19 percent patients visit twice in a month and 29.3 percent patients visit the clinic whenever they require they do visit for the consultation. 86.1 percent of the patients did not feel any problem in the hospital as compared to 13.9 percent patients who mentioned problems in the hospital like late arrival of Doctor, non-availability of medicines, long waiting time for consultation, and late registration. 62.1 percent of the patients visit hospital by bus, 25.9 percent by rail and 12.1 by their own means of transport.

\section{Impact analysis of treatment}

Utilization Time: 32.8 percent and 24.1 percent patients strongly disagree and disagree respectively which indicate that more than 50 percent patients were utilizing their time in the useful manner. Only about the 39.7 percent patients (agree 27.6 percent and strongly agree 12.1 percent) agreed about that they were not utilizing their time in the useful manner before the treatment. Similarly as treatment began 48.3 percent patients $(32.8+15.5)$ begin to use their time usefully with the treatment as compared to 48.3 percent of PLWE did not use their time usefully. 
Stigma in the family and Community: Stigma is normally is associated with such patients. More than 56 percent people with epilepsy (PLWE) expressed that they did not felt any stigma in the community or in the neighborhood area before the treatment; in contrast about 36.4 percent PWE felt stigmatized in the community. Similarly about 53.4 percent PWE did not felt any stigma in the family before the treatment whereas 41.3 percent PLWE expressed discrimination due to the disease in the family.

Table 3: Impact Analysis of Epilepsy Treatment (percent):

\begin{tabular}{|c|c|c|c|c|c|}
\hline Indicators & SD & D & A & SA & DK \\
\hline $\begin{array}{l}\text { Not using time usefully before treat- } \\
\text { ment }\end{array}$ & $\begin{array}{l}24 . \\
1\end{array}$ & $\begin{array}{l}32 . \\
8\end{array}$ & $\begin{array}{l}27 . \\
6\end{array}$ & $\begin{array}{l}12 . \\
1\end{array}$ & 3.4 \\
\hline Not using time usefully with treatment & $\begin{array}{l}32 . \\
8\end{array}$ & $\begin{array}{l}15 . \\
5\end{array}$ & $\begin{array}{l}34 . \\
5\end{array}$ & $\begin{array}{l}13 . \\
8\end{array}$ & 3.4 \\
\hline $\begin{array}{l}\text { Before Treatment felt stigmatized in } \\
\text { community }\end{array}$ & 31 & 25 & 19 & $\begin{array}{l}17 . \\
2\end{array}$ & 6.9 \\
\hline $\begin{array}{l}\text { Before Treatment felt stigmatized in } \\
\text { family }\end{array}$ & 8.6 & $\begin{array}{l}44 . \\
8\end{array}$ & $\begin{array}{l}24 . \\
1\end{array}$ & $\begin{array}{l}17 . \\
2\end{array}$ & 5.2 \\
\hline $\begin{array}{l}\text { Family understood the Disease before } \\
\text { treatment }\end{array}$ & $\begin{array}{l}32 . \\
8\end{array}$ & $\begin{array}{l}20 . \\
7\end{array}$ & $\begin{array}{l}17 . \\
1\end{array}$ & $\begin{array}{l}24 . \\
1\end{array}$ & 5.2 \\
\hline $\begin{array}{l}\text { Family understood the Disease with } \\
\text { treatment }\end{array}$ & 19 & $\begin{array}{l}25 . \\
9\end{array}$ & 31 & 15 & 8.6 \\
\hline $\begin{array}{l}\text { Relationship with other affected due to } \\
\text { Disease }\end{array}$ & $\begin{array}{l}27 . \\
6\end{array}$ & $\begin{array}{l}15 . \\
6\end{array}$ & $\begin{array}{l}22 . \\
4\end{array}$ & $\begin{array}{l}17 . \\
2\end{array}$ & $\begin{array}{l}17 . \\
2\end{array}$ \\
\hline $\begin{array}{l}\text { Positive impact on relationship with } \\
\text { treatment }\end{array}$ & $\begin{array}{l}36 . \\
2\end{array}$ & $\begin{array}{l}15 . \\
5\end{array}$ & $\begin{array}{l}20 . \\
7\end{array}$ & $\begin{array}{l}17 . \\
2\end{array}$ & $\begin{array}{l}10 . \\
3\end{array}$ \\
\hline Afraid to work before treatment & $\begin{array}{l}10 . \\
3\end{array}$ & $\begin{array}{l}24 . \\
1\end{array}$ & 19 & $\begin{array}{l}41 . \\
4\end{array}$ & 5.2 \\
\hline Afraid to work with treatment & $\begin{array}{l}10 . \\
3\end{array}$ & $\begin{array}{l}41 . \\
4\end{array}$ & 3.4 & $\begin{array}{l}27 . \\
6\end{array}$ & $\begin{array}{l}17 . \\
2\end{array}$ \\
\hline Income increase with treatment & $\begin{array}{l}32 . \\
8\end{array}$ & $\begin{array}{l}29 . \\
3\end{array}$ & 19 & 6.9 & $\begin{array}{l}12 . \\
3\end{array}$ \\
\hline Treatment expenditure is difficult & $\begin{array}{l}10 . \\
3\end{array}$ & $\begin{array}{l}44 . \\
8\end{array}$ & 19 & $\begin{array}{l}17 . \\
2\end{array}$ & 8.6 \\
\hline Difficulty to visit the clinic/hospital & 19 & $\begin{array}{l}44 . \\
8\end{array}$ & $\begin{array}{l}10 . \\
3\end{array}$ & $\begin{array}{l}22 . \\
4\end{array}$ & 3.4 \\
\hline
\end{tabular}

(SD: Strongly Disagree; D: Disagree; A: Agree; SA: Strongly Agree; DK: Do not know)

Knowledge about the Epilepsy: Knowledge about the disease is an important factor in caring the PLWE in the family. It plays an important role in life of Patient. Family of more than fifty three percent PLWE did not have better understanding about the disease whereas 41.2 percent of the family members of PLWE have an understanding about the disease and its consequences before the treatment (Table-2). As the treatment consultation began then 44.9 percent family of PLWE still did not know about the disease as compared to 46 percent of family of PLWE have expressed that their family have understood the disease as the treatment began. Relationship with other: 43.2 percent PLWE expressed that their relationship with other has not affected because of the disease whereas 39.6 percent mentioned that their relationship has been affected due to the disease before the treatment. As the treatment began then relationship of 51.4 percent of PWE with other does not have any positive affect and 37.9 PLWE percent expressed the positive impact on the relationship with others. It appears that treatment doesn't have any positive impact on the relationship rather it may have negative impact as PLWE become more visible after the treatment (Table-3).

Capacity to Work: Generally PLWE are scared to do work because of their disease. 34.4 percent of PLWE were working easily without any trouble due to the disease whereas 60.4 percent PLWE expressed their fear to do the work before the treatment (Table3).More than fifty percent (51.7) percent of PLWE said that they do not fear while doing any work in contrast to 31 percent PLWE still afraid to do work because of the disease after the treatment. Income, expenditure and hospital visit: There is no increase in the income of the 62.1 percent of PLWE on the treatment of the disease where as 25.9 percent of PLWE expressed that their income has increased due to the treatment. About 55.1 percent of the PLWE said the treatment of the disease is not much difficult as compared to 36.2 percent PLWE felt difficulty in meeting the treatment expenditure. Further PLWE from the neighboring dis- tricts also expressed difficulty in visiting clinic or hospital. More than fifty five percent of the PLWE do not have any difficulty in visiting the hospital or other clinic whereas 32.7 percent of the PLWE have expressed difficulty in visiting the hospital (Table-3). PLWE and Community Involvement: There are problems associated with PLWE in interaction with other people in the family as well as in the community. We tried to find out the pattern of their involvement in the community (Table-4). More than Fifty percent PLWE did not interact with other community people. About 17 percent of the PLWE each involve themselves more than normal and less than normal where as 13.8 percent PLWE involve normal time in the community before the treatment. But 31 percent each of the PWE involve not at all and their normal time in the community and 22.4 percent PLWE involve less than normal time in the community and 15.5 percent of the people involve their time more than normal after the treatment (Table-4).

Table 4: Pattern of Normal involvement in the Community:

\begin{tabular}{|c|c|c|c|c|}
\hline \multirow[t]{2}{*}{ Patient Pattern of Normal involvement } & \multicolumn{2}{|c|}{$\begin{array}{l}\text { Before Treat- } \\
\text { ment }\end{array}$} & \multicolumn{2}{|c|}{$\begin{array}{l}\text { After Treat- } \\
\text { ment }\end{array}$} \\
\hline & No. & $\%$ & No & $\%$ \\
\hline Not at all & 30 & 51.7 & 18 & 31 \\
\hline $\begin{array}{l}\text { A normal amount of time in the com- } \\
\text { munity }\end{array}$ & 8 & 13.8 & 18 & 31 \\
\hline $\begin{array}{l}\text { Less than normal amount of time in } \\
\text { community }\end{array}$ & 10 & 17.2 & 13 & 22.4 \\
\hline $\begin{array}{l}\text { More than normal amount of time in } \\
\text { community }\end{array}$ & 10 & 17.2 & 9 & 15.5 \\
\hline Total & 58 & 99.9 & 58 & 99.9 \\
\hline
\end{tabular}

\section{Discussion}

This paper emphasized the socio-cultural determinants-cultural beliefs associated with epilepsy. Besides family based Treatment pattern, patients transport system and its expenditure on hospital visit and impact has been analyzed. It has also investigated the behavior, social burden of care in family, economic decision making, education and influences of peer groups and problems in employment. It also assessed knowledge about epilepsy, local healing practices and associated faith-spirit possession relating to epilepsy and stigma prevalent. The average age of PLWE patients ranges from 19 to 28 years. Most of them were male and female patients were very less belonging to the rural area of the district as compared to 39 percent patients from the urban areas. Ninety percent of patients with epilepsy are unmarried, 63 percent PWE belong to Hindus, followed by Muslim and Christian. Mostly patients as well as their father are educated.

Family based treatment pattern have been explored for age of first seizure, duration of patients suffering due to epilepsy and treatment pattern and traditional knowledge about the epilepsy. Most of the patients have expressed the first episode of seizure between 16 to 20 years followed by 11 and 15 years of the age. The duration of suffering ranges from five years to 20 years among the people with epilepsy.

All patients took the allopathic or homeopathic treatment, and they have heard about epilepsy, but not ever thought as it is a disease. Near 38 percent PLWE expressed it as supernatural illness as compared to 80 percent thought it as disease like other diseases. It has disturbed the daily routine of the patients in 47 percent cases and more than 50 percent do not wish to marry due to epilepsy About the 31 percent PLWE sought the treatment from the Molvie and they also visited the religious sites- masjid, mazar etc. for anemia. About 66 percent of patients Family are capable to some extend the economic expenditure of patients as compared to 28 percent family of patients was not economically capable to meet the treatment expenses. Further similar aspects were observed in case of jobs of these patients and family worry about the disease.

Hospital visit of patient reveals significant aspects. Such as nearly 45 percent patients were from Bareilly district and remaining was from the neighboring districts. Most of the patients take one hour to $3.5 \mathrm{hrs}$ to reach hospital and spend 50 to $150 \mathrm{Rs}$ for one way. Patients are accompanied by the Father followed by Mother, 
Brother but no Sister accompanies the patient. Relatives also accompany them if kin family members fail. Only 6.9 percents patients visit hospital with relative. Patients are referred by the Doctor followed by relatives and neighbors. 66 percent patients have visited the hospital for the first time consultation. About 66 percent patients have been visiting hospital for the five months. 51.7 percent patients visit hospital once in a month and 29.3 percent patients visit the clinic whenever they require. Nearly 57 percent patients have been benefitted from the treatment. Further 48.3 percent patients felt treatment benefit was much more whereas 37.9 percent patients felt benefit was less. Impact of treatment has been analyzed on various activities before and after treatment began. More than 50 percent patients used their time usefully before the treatment as compared to 40 percent who had not utilized their time usefully. As treatment began nearly 40 percent began to use their time in useful ways. Nearly 56 percent PLWE did not felt any stigma in community before the treatment in contrast to 36 percent patients felt stigma in the community and family.

Knowledge and understanding about the disease is an important factor play an important role in life of Patient. Family of more than fifty three percent PLWE did not have better understanding about the disease.

The relationship of 43.2 percent PLWE had not affected due to disease prior to treatment. After treatment began then relationship of 51.4 percent of PWLE did not have felt any positive improvement in contrast to 37.9 percent of PLWE expressed the positive impact on the relationship with others. It appears that treatment doesn't have any significant impact on the relationship. PLWE are scared to do work because of their disease. 60.4 percent of PLWE expressed their fear of epilepsy before the treatment in contrast to 31 percent still afraid to do work because of the disease after the treatment. There is no improvement in earning among the PLWE even after the treatment. There are problems of interaction with other people in family as well as in community.

\section{Conclusion}

We conclude that PLWE have many problems dealing with everyday life, mainly concerning the socio-cultural determinants. They are stigmatized in the family as well as in the Community on one hand and on other hand they remain in state of fear to do daily routine work. As epilepsy is an unpredictable disease and requires continuous and long term medications which lead to complications in their life. It has been observed that all family members were disturbed due to his disease, particularly of its uncertainty and longevity of treatment.

Further, there is scope for the advance research and to explore that how they are living as married people and carrying out their daily mundane work. Similarly, other important aspects can also be explored among women, pregnant women and issues of children with epilepsy and their social consequences.

\section{Acknowledgement}

We are thankful to University Grant Commission (UGC), New Delhi for the Award of Minor Research Project Grant to first Author (AR). Further, we also express gratitude to our colleagues $\mathrm{Dr}$ Vibha Sharma, Associate Professor of Clinical Psychology and Dr Sarbjeet Khurana, Associate Professor and Head of Department of Epidemiology, IHBAS, New Delhi for their valuable comments and constructive criticisms to the earlier drafts.

\section{References}

[1] Degen R, Degen HE, Roth C. (1990). some genetic aspects of idiopathic and symptomatic absence seizures: waking and sleep EEGs in siblings. Epilepsia. 31(6):784-94.

[2] Gourie-Devi,M, G.Gururaj and P Satishchandra (2004). Delivery of Epilepsy Care to the Community: Towards the national Epilepsy con- trol Programme. In Mental Health-An Indian perspective (19462003) Ed. S P Aggarwal, DGHS, Ministry of H \& FW, New Delhi.

[3] Gourie-Devi,M, G.Gururaj, P Satishchandra and D K Subbhakrishna(2004). Prevalence of Neurological Disorders in Bangalore, India: A Community - Based Study witrh a comparison between Urban and rural Area. Neuroepidemiology 2004; 23:261- 268.

[4] Pal, D K ; Das T., Sengupta, S(1998). Comparison of Key informant and Survey methods for ascertainment of childhood Epilepsy in west Bengal, India. International Journal of Epidemiology, 27,672-6.

[5] Pal, D K; Nandy, S; Sander, J.W.A.S. (1999). Towards a coherent public health analysis for Epilepsy. Lancet, 353; 1817-8.

[6] Rani, Ajita (2012): Psychosocial study of Epilepsy- specific Beliefs, Attitudes and Behavior in Rural Communities in the Districts of North India. Minor Research Project Report (2012), UGC, New Delhi (Unpublished).

[7] Sridharan, R. (2002). Epidemiology of epilepsy. Current Sciences. Vol 82.No.6, 664-670. 